\title{
A Framework of Building Effective MOOCs
}

\author{
Ming Zhao \\ School of Air Transportation, Shanghai University of \\ Engineering Science, \\ Shanghai, China \\ jmmolly_zhao@163.com
}

\author{
Jing $\mathrm{Wu}$ \\ School of Information Science \& Technology, Donghua \\ University \\ Shanghai, China \\ wj929350@163.com
}

\author{
Xiaodan Huang \\ School of Air Transportation, Shanghai University of Engineering Science \\ Shanghai, China \\ 819028903@qq.com
}

\begin{abstract}
Massive Online Open Courses or MOOCs might be one of the most popular ways on e-learning, which facilitate to access quality education for learners residing in far or disadvantaged areas. MOOCs have several modes for providing learning resources, but not all courses could meet student goals. To MOOCs designers and managers, it's important to build an effective MOOC, that how to identify the effectiveness of a MOOC is equally important. The MOOCs stakeholders face arge of opportunities and challenges. In this paper, firstly we analyze the evolution of MOOCs including types of MOOCs, development stages of MOOCs, evaluation dimension to an effective MOOC, and automated tools for MOOCs delivery or assessment. Next we conclude main challenges and affected factors to MOOCs stakeholders in MOOC design, delivery, and assessment for improving the quality of MOOC. Finally we propose a framework where could help each MOOCs stakeholder clear the main task or critical affected quality factors.
\end{abstract}

Keywords-MOOC; effectiveness; quality; evaluation; framework

\section{INTRODUCTION}

MOOC is an acronym that stands for "Massive Online Open Course", when one of online courses reach more than 2,000 enrollments, which was first proposed by Dave Cormier in 2008. As a continuation of the use of technology initiated by distance and online learning, MOOCs base on Open Education Resources (OER) and the extensive use of modern video production. Supporting with several course platform and social interaction tools, such as Coursera, Edx, Miriada X, and Udacity, a large numbers of self-organizing learners could share course resources. Since 2012, several large Universities have started to build their own MOOCs. Therefore, MOOCs might be one of the most versatile ways to offer access to quality education, which provide learning opportunities for large numbers of learners, especially for those residing in far or disadvantaged areas. Differently from the highly organized and structured classroom, MOOCs are free, no entry requirements and fragmented information. Most students decide to enroll in a MOOC because it requires no attendance, and can be accessed from anywhere anytime with a device connected to Internet.
In the past few years, there are a large amount of active MOOCs implemented with different structure and methodology on the Internet. According to the courses features, the widely accepted model classification proposed in 2012 was $\mathrm{xMOOC}, \mathrm{cMOOC}$ and quasi-MOOC, as in [1], where ' $\mathrm{x}$ ' stands for extended and ' $c$ ' stands for connectivism. In 2013, Conole and Clarke put forward a framework to categorize MOOCs on multiple dimensions, which are eight categories MOOCs including Transfer MOOCs, Made MOOCs, Synch MOOCs, Asynch MOOCs, Adaptive MOOCs, Group MOOCs, Connectivist MOOCs and Mini MOOCs, as in [2]. In 2015, the impact of learner motivation on MOOC preference between Transfer MOOCs and Made MOOCs had been researched, as in [3].

With a higher rate of emerging MOOCs, learners are required to identify the MOOC which could best meet the learners' goals in learning. To MOOCs designers and managers, there are large of opportunities and challenges never faced before. Therefore, it's important to identify the related factors which form the effectiveness of a MOOC in different stage.

In this paper, firstly we analyze the evolution of MOOCs including types of MOOCs, development stages of MOOCs, evaluation dimension to an effective MOOC, and automated tools for MOOCs delivery or assessment. Next we conclude main challenges and affected factors to MOOCs stakeholders in MOOC design, delivery, and assessment for improving the quality of MOOC. We aimed to propose a framework where each MOOCs stakeholder could explore an effective MOOC and clear the main task or critical affected quality factors.

\section{EvOlution OF MOOCs}

Since 2008, the impact of MOOC has been disruptive in the domain of education. Relevant research has matured gradually including taxonomy of MOOCs, effectiveness of MOOCs, automated tools for MOOCs, etc.

\section{A. Types of MOOCs}

There are different kinds of MOOCs based on different methodology. 
Initially, the common three categories is $\mathrm{xMOOC,} \mathrm{cMOOC}$ and quasi-MOOC. xMOOC which were professor-centric relate to the university context. That is to say, their structure and methodology are the same as university courses. xMOOCs allow people to acquire first-level knowledge about a concrete theme, and to earn a course completion certificate that proves that knowledge acquisition. Almost all top university own a great number of $\mathrm{xMOOC}$ courses. cMOOC were on a peer to peer basis, and stressed on connectivism. Therefore, these courses are based on the theory of digital learning and relevance theory, with a more open structure, without the use of assessment tests. cMOOCs are great online communities where participants interact and discuss in groups for creating and improving the course content. Quasi-MOOC may be the mix of the previous ones, which stress the use of students' skills to complete activities or solve problems. In these courses, students can consult a set of learning materials and must carry out several tasks. Therefore, quasi-MOOC also is known as task-based MOOCs. Some of them require students to complete successfully the activities. At the same time, students can get support from the instructors or the community itself in order to solve problems.

More recently, there has been a more extensive taxonomy of MOOCs by Conole (2013) and Clarke (2013), as in [2] [3] [4]. The newly eight categories of MOOCs are as follows:

- Transfer MOOCs: existing classroom lectures are transferred to a MOOC.

- Made MOOCs: extensive use of video and interactive material, and made exclusively as a MOOC.

- Synch MOOCs: with a fixed start and end date.

- Asynch MOOCs: without a fixed start and end date, and have more flexible assignment deadlines.

- Adaptive MOOCs: providing personalized learning experiences.

- Group MOOCs: focus on collaboration in small groups

- Connectivist MOOCs: emphasis on connection across a network of peers.

- Mini MOOCs: smaller than the traditional MOOC, and less time, shorter videos and shorter contents.

At present, Transfer MOOCs, Made MOOCs and Mini MOOCs are relatively insignificant usage in China. ICOURSE is the stance of Made MOOCs.

\section{B. Stage of MOOCs}

In this section, we review previous literatures and conclude distinct features or main tasks of the design, delivery and assessment of MOOC, as in [5] [6].

1) Design: Although many MOOC formats exist, most courses exhibit common characteristics including massive participation, online and open access, short videos and automated assessment, etc. The course designers should collect information like usage patterns, navigation, content sequencing, data formats, tool usage and students' profiling which could help designers improve MOOC usage in future.
2) Delivery: MOOCs are intended for thousands of simultaneous participants in the world, so the delivery of courses is quite a complex task, which requires completely adapting the traditional tutor-assisted e-learning model. Data related to individuals' online behavior should be stored at learning management system, which could provide insight into student learning processes and alert educators to intervention appropriately.

3) Assessment: With large numbers of learners in MOOC, it's not possible for human tutors to follow up with every student and grade assignments individually. The computerbased grading is insufficient and partial. To e-learning learners, they want to know more about their learning process and more feedback besides formal assessment. So the MOOC test content must be changed for every learner to be suitable for learner's profile and reduce cheating

\section{Evaluation Of an Effective MOOC}

Though thousands of users have enrolled to the MOOCs, not all the MOOCs meet the goals of users. It has found that there is considerable quality variation between different MOOC platforms and among courses in the same platform as well. In previous research, there are many quality evaluation methods in eLearning field. However, those aspects are not suitable for MOOC due to its unique features like for example amount of enrollments, different origin and education level, and so on.

The research conducted by Yousef (as in [7]) evaluate MOOC quality in 2 dimensions, one is pedagogical criteria, the other is technical criteria. Then the two dimensions were subdivided 6 categories, which were instructional design, assessment, user interface, video content, learning and social tools, and learning analytics. Their statistic results showed that the learning analytics and assessment categories were more important than other categories.

The latest quality dimensions for online learning contains 8 dimensions which are course overview and introduction, learning objectives, assessment and measurement, instructional materials, learner interaction and engagement, course technology, learner support and accessibility as in [8].

Although the 8 dimensions provide a quality framework for online learning, it does not specifically address the context of MOOC. Then Grounded Theory was incorporated in MOOC by Adamopoulos (as in [9]) who uses user generated online reviews to find the factors to an effective MOOC.

Researchers founded that Grounded Theory provides an opportunity whereby they can become more closely attuned to empirical data. Then a 10 dimensions which affects to an effective MOOC were presented by Gamage (as in [6]). These categories will assist in designing and implementing an effective MOOC

1) Technology dimension: which was explained the ability to continue learning in MOOC with the existing hardware and software.

2) Pedagogy dimension, which was explained the method of MOOCs learning delivery and the delivery management. 
3) Motivation dimension, which was explained the motivation to use the MOOC courses. That is to say, whether the participants could keep the attention to the learning and satisfy with the overall course.

4) Usability dimension, which was identified by the interface design, navigation interactions, learning environment and the facility to obtain feedback about any issue.

5) Content or Material dimension, which was explained effectiveness by providing useful and relevant up-to-date content, apart from the rich multimedia and collaborative content.

6) Support for learner dimension, which was defined as psychological and social support for the learners, such as administrative support and a proper complaints procedure.

7) Assessment dimension, which was identified by collaboration assessment, mastery of the content, periodic assessment and satisfaction assessment.

8) Future directions or Networks dimension, which revealed the credentials or recognitions for MOOC students' achievements whereby give them new opportunities to other interest network.

9) Collaborative dimension, which was explained as the effectiveness that the students collaborate with other students, instructor and the institution.

10) Interactivity dimension, which was explained as the possibility a student could interact directly with other students or instructor.

\section{Use of Agents in MOOCs}

Above all, MOOCs designers and providers face challenges never happened before, which need further research. Because of the characteristics of MOOCs, automated tools like agents are used to optimize efficiency, reduce costs and improve the learning process. Software agents can use artificial intelligence methods to analyze information and react it, as well as cooperate with other agents.

1) Agents in MOOC Design: In this stage, software agents should interpret information on course usage and collect feedback to help the MOOC designers improve course content for future learners.

2) Agents in MOOC Delivery: Firstly, software agents should understand learners' learning style and customize content according to the learners' profile, while getting personalized feedback for improving their performance and their motivation. Therefore, some machine learning algorithms are applied to implement adjusting course content, changing course content parameters, or showing relevant case studies or further readings in delivery stage. Secondly, agents should provide data analysis on the basis of learners' online information for detecting their performance trends and deviation, then could alert human tutors about anomalies, potential drop-outs, cheating or outstanding learners.

3) Agents in MOOC assessment: In assessment stage, software agents should adjust assignment questions according to the learners' educational level, or changing the sequencing of the question. Intelligent agents could also improve identity verification and reduce fraud and cheating during test.

\section{PROPOSED FRAMEWORK}

For high quality education, it is important to improve the curriculum design, delivery and evaluation. In addition, different stakeholders are involved in different stages, each stakeholder is responsible for one or more course content.

\section{A. Main Challenge for Stakeholders}

To different MOOC stakeholders, they are all faced with challenges never faced before. According to the design, delivery and assessment of MOOCs, we generalize the main challenge of each stage presents, as shown in Fig. 1.

In design stage, course designers are responsible for providing course usage and improving MOOC usage according to learners' feedback, which could be supported by software agents.

In delivery stage, course designers and platform managers are both responsible for the personalized content according to the students' profile, knowledge background and educational preferences. Software agents using machine learning algorithm are used to monitor learners' process and detect potential anomalies, and provide an intelligent tutoring systems to guide a learner in his or her learning process anytime, anywhere. Human tutor organize the weekly discussion and final summary.

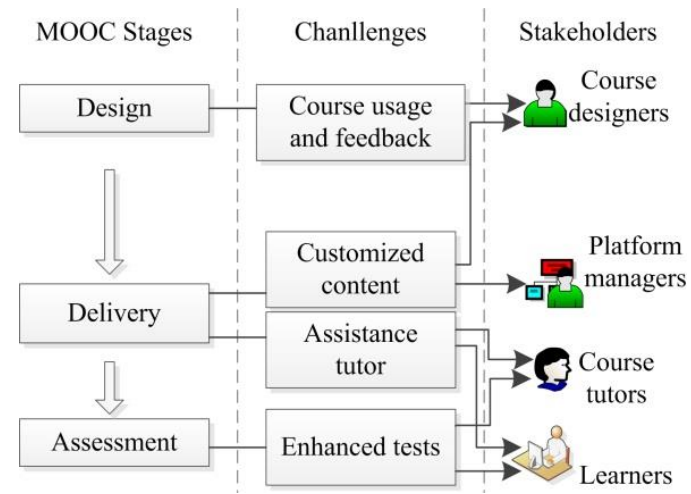

Fig. 1. The main challenge of each MOOCs stage are for every stake-holders

In assessment stage, course tutors design the test questions, but traditional test options are limited, automated assessment tools could be used to adjust questions to different learners for reducing fraud and cheat in test.

\section{B. Quality Metrics for Stake-holders}

In addition, it is found that there is considerable mass variation between different MOOC platforms, or at the same platform courses. According to the 10 dimensions presented by Gamage [6], which are influential to the MOOC quality, we identify the factors to each stakeholder, then each stakeholder could think these factors as a quality metrics framework for operating an effective MOOC, as shown in Fig. 2.

Course designers are primarily responsible for the MOOC learning delivery management, providing useful and relevant up-to date content, the usability of MOOC and future directions. 
Platform managers could provide just-in-time technical supporting for learners, which give the learners chance to collaborate and interact with other learners.

Course tutors guide and supervise the learning process, then give the periodic assessment to learners. Sometime is human tutor, sometime is the software agent.

In some qualitative study show that most of the learners had chosen courses outside their current area of work or study, the learners' intrinsic motivation is a driver of effective learning which was measured in terms of course completion and grades [3].

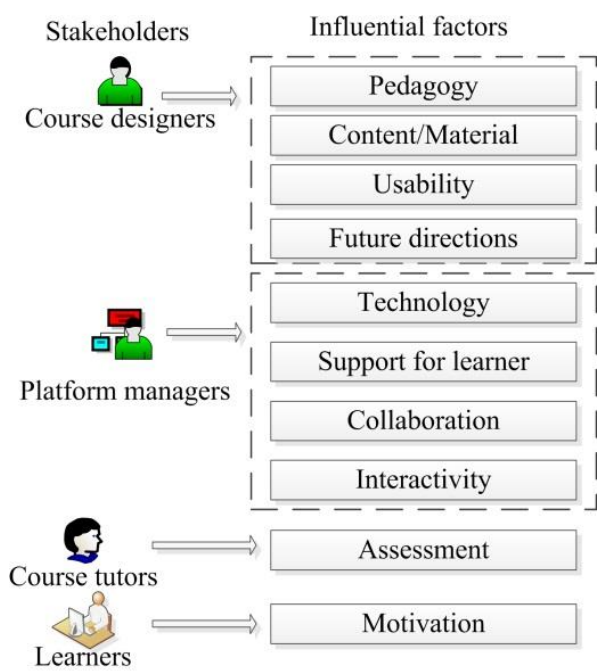

Fig. 2. A quality metrics framework for operating an effective MOOC

\section{CONCLUSION}

Obviously, MOOCs will become a regular feature in online open educational resources. MOOC designers have offered MOOCs in different styles and formats. However, not all the MOOCs meet the goals of user. It is vital to research what will affect an effective MOOC. We explore previous literatures relating to quality of MOOCs, then we analyze and conclude the popular eight categories of MOOCs, especially Transfer
MOOCs, Made MOOCs and Mini MOOCs are relatively insignificant usage in China. In this research, we mainly answered to the problem "How to operate an effective MOOC?" So we comparatively analyze the evaluation dimensions of an effective MOOC, and to improve efficiency in MOOCs, we analyze the use of agent in different MOOC stages. Finally, according to the MOOC stages and evaluation dimension, we conclude main challenge for different MOOC stakeholders, then present a quality framework which gives metrics for each MOOC stakeholders from design to management. We think the proposed framework could improve the use of existing MOOCs or future MOOCs.

\section{REFERENCES}

[1] Rodriguez, C.Osvaldo,"MOOCs and the AI-Stanford Like Courses: Two Successful and Distinct Course Formats for Massive Open Online Courses," Europe Journal of Open, Distance and E-Learning,(2012):13.

[2] Conole, Gráinne,"MOOCs as disruptive technologies: strategies for enhancing the learner experience and quality of MOOCs," Revista de Educación a Distancia, vol. 39,pp. 1-17,2013.

[3] D. G. Sooryanarayan and D. Gupta, "Impact of learner motivation on MOOC preferences: Transfer vs. made MOOCs," 2015 International Conference on Advances in Computing, Communications and Informatics (ICACCI), Kochi, 2015, pp. 929-934.

[4] Clark D. MOOCs: taxonomy of 8 types of MOOC.[online]. Available: http://donaldclarkplanb.blogspot.co.uk/.

[5] G.Siemens, “Open educational resources: innovation, research and practice,’British Journal of Educational Technology,2013, 44(5):E174E175.

[6] Dilrukshi Gamage, Shantha Fernando, Indika Perera, "Factors leading to an effective MOOC from participants perspective,"in international conference on Ubi-media computing,2015,pp.230-235.

[7] A F Yousef, M, A Chatti,U Schroeder, and M Wosnitza, "What Drives a successful MOOC? An Empirical Examination of Criteria to Assure Design Quality of MOOCs," in Advanced learning Technologies(ICALT)IEEE 4th International Conference,2014,pp.44-48.

[8] K Shattuck. (2014)Quality Matters Programe. [Online]. http://www.qualitymatters.org/rubric.

[9] P Adamopoulos, "What makes a great MOOC? An interdisciplinary analysis of student retention in online courses," in Thirty fourth International Conference on Information Systems, Milan, 2013,pp.1-21. 